\title{
Default and enforcement constraints ${ }^{1}$
}

\section{Fabrizio Perri}

\section{University of Minnesota, Federal Reserve Bank of Minneapolis, NBER and CEPR}

\begin{abstract}
This article illustrates when limited enforcement of contracts induces enforcement constraints (limits to intertemporal exchange) or default (the breaking of intertemporal promises with the associated punishment), and sheds light on how enforcement policies should be related to the observed frequency of default. When limited enforcement is the only friction, equilibrium default is never observed, yet tightening enforcement of contracts is socially beneficial. When limited enforcement coexists with other frictions, default occurs in equilibrium, but tightening enforcement might be socially undesirable. The reason is that equilibrium default, although detrimental to intertemporal exchange, might lead to improved allocation of resources across states.
\end{abstract}

Intertemporal exchange, that is the exchange of resources today for a promise of resources at a later date in a given state, is key for promoting economic efficiency. For example, to finance an investment, a government borrows capital abroad in exchange for a promise of repayment once the investment has paid off. Or, to finance consumption, an individual who loses her job borrows resources in exchange for the promise of repayment once she gets a new job. If the enforcement of promises is limited, the extent of intertemporal exchange can be reduced by so-called enforcement constraints and, under some conditions, default, that is, the breaking of promises, can arise. This article presents a simple general equilibrium set-up to analyse these issues and provide some direction for the design of enforcement policies. Key references for the theory of limited enforcement without default are Kehoe and Levine (1993), Kocherlakota (1996) and Alvarez and Jermann (2000), while for limited enforcement with default see Zame (1993) and Dubey, Geanakoplos and Shubik (2005).

\section{The set-up}

The goal of this set-up is to capture the need for intertemporal exchange, as described in the examples above. There are two agents which live for two periods and consume a single good.

Agent 1, the borrower, owns a technology such that, if $k$ units of the good are invested in period 1 , $A k^{\alpha}, 0<\alpha<1$, units are produced in period 2, where $A$ is a random variable realized in period 2, with positive support and distribution $F(A)$ known to both agents. Agent 2, the lender, is endowed

\footnotetext{
${ }^{1}$ Entry prepared for the "The New Palgrave Dictionary of Economics”, 2nd edition, edited by S. Durlauf and L. Blume, Palgrave Macmillan (Basingstoke and New York)
} 
with $e$ units of the consumption good in period 1. Consumption allocations of agent $i$ are consumption at date $1, c_{i 1}$ and the function $c_{i 2}(A)$ which assigns period 2 consumption for each possible realization of $A$. Borrower's utility is given by $u\left(c_{11}\right)+\int u\left(c_{12}(A)\right) d F(A)$ where $u$ is a concave utility function satisfying Inada conditions. The lender has linear utility given by $c_{21}+\int c_{22}(A) d F(A)$. Linear utility implies that lender's equilibrium utility is constant across different market structures so that borrower's utility is the only statistic needed to Pareto-rank equilibria. In all the economies described below the following resource constraints hold

$$
\begin{aligned}
c_{11}+c_{21}+k & =e \\
c_{12}(A)+c_{22}(A) & =A k^{\alpha} \quad \text { for every } A
\end{aligned}
$$

\section{A frictionless benchmark}

Assume agents can trade a complete set of Arrow-Debreu promises which are fully and costlessly enforceable. The budget constraints of the borrower are

$$
\begin{gathered}
c_{11}+k=\int p(A) d F(A) \\
c_{12}(A)=A k^{\alpha}-p(A) \quad \text { for every } A
\end{gathered}
$$

where $p(A)$ denotes the amount that the borrower promises to repay in state $A$. Equilibrium

allocations display complete risk sharing, that is, the ratio of marginal value of consumption of the two agents is constant across dates and states of the world. We denote with $c^{A D}$ the constant, across dates and states, level of consumption of the borrower in this economy.

\section{Limited enforcement}

This section describes an economy denoted as ADLE (Arrow-Debreu Limited Enforcement) and shows that limited enforcement prevents full risk sharing, reduces investment and welfare. Assume that in period 2 the borrower can walk away from any promise made to the lender by suffering a default deadweight cost proportional to her output and equal to $\delta A k^{\alpha}$ where $\delta>0$ is a parameter that measures the strength of enforcement. This implies that any Arrow-Debreu promise $p(A)>\delta A k^{\alpha}$ will not be honoured by the borrower and thus will not be purchased by the lender. Also, promises satisfying $p(A) \leq \delta A k^{\alpha}$ will be fully honoured and priced as in the frictionless economy. So limited enforcement limits the use of state-contingent promises but does not induce default. A convenient way of capturing this, following Alvarez and Jermann (2000), is to assume that the borrower faces constraints on the sales of each promise so to guarantee no default. These enforcement constraints have the form

$$
p(A) \leq \delta A k^{\alpha} \quad \text { for every } A
$$


as the borrower can sell each promise only up to the point where the cost of keeping it is equal to the cost of defaulting on it. Equilibrium allocations can be characterized by substituting budget constraints (1) and (2) into the borrower's utility and taking first-order conditions with respect to $k$ and $p(A)$ subject to constraints (3). This yields

$$
u^{\prime}\left(c_{11}\right)=\int\left[A \alpha k^{\alpha-1} u^{\prime}\left(c_{12}(A)\right)+A \alpha k^{\alpha-1} \delta \mu(A)\right] d F(A)
$$

where

$$
\mu(A)=u^{\prime}\left(c_{11}\right)-u^{\prime}\left(c_{12}(A)\right)
$$

are the Lagrange multipliers on the enforcement constraints. If the cost of default $\delta$ is sufficiently small and the distribution of $A$ is sufficiently spread out, $c_{11}=c_{12}(A)=c^{A D}$ is not a solution of (3) and (4) as enforcement constraints on the high $A$ promises would be violated. The solution is then characterized by a level of productivity $A^{*}$ such that for all $A>A^{*}$ enforcement constraints are binding and $c(A)=(1-\delta) A k^{\alpha}>c_{11}$. For $A \leq A^{*}$ enforcement constraints are not binding and $c(A)=c_{11}<c^{A D}$. Complete risk sharing involves the borrower selling promises to repay in states with high $A$, in order to finance consumption today (when she has no output) and consumption tomorrow in states with low $A$. But if the distribution of $A$ is spread out complete risk sharing calls for promises of a large transfer of resources from the borrower to the lender in the states with high $A$. When enforcement is limited ( $\delta$ is low) the lender, in period 1 , correctly anticipates that these transfers will not be made and buys a smaller amount of the promises. So, relative to complete risk sharing, the borrower has fewer resources in period 1 and in the period 2 states with low $A$, but consumes more in period 2 states high $A$. This allocation of consumption increases the marginal value of resources in period 1 relative to the expected marginal value of resources in period 2 and thus reduces $k$ relative to the full enforcement case. Finally, equilibria in economies with strong enforcement (high $\delta$ ) Pareto-dominate equilibria with weak enforcement (low $\delta$ ). To see this, note that the equilibrium allocation in the weak enforcement economy is budget-feasible and satisfies the enforcement constraints in the strong enforcement economy, so, if it is not chosen, it must yield the borrower lower utility.

ADLE economies have been used extensively in a variety of applications such as asset pricing (Alvarez and Jermann, 2000), international business cycles (Kehoe and Perri, 2002) and consumption inequality (Krueger and Perri, 2006). All these studies show that limited enforcement prevents complete risk sharing, and for this reason allocations in ADLE economies can reproduce the data better than allocations in standard Arrow-Debreu economies. ADLE economies, though, cannot be used to understand equilibrium default (that is, the actual break of a promise and the 
suffering of the associated cost) as the trade in contingent promises makes incurring the default cost unnecessary. In order to understand when default arises and what its consequences are, the next section considers an economy in which contingent promises cannot be traded, either because markets are exogenously missing or because the borrower has private information about realizations of $A$.

\section{Limited enforcement and non-contingent promises}

The borrower finances consumption and investment only by selling a non-contingent promise $p$ which can be defaulted on in state $A$ by suffering the default cost $\delta A k^{\alpha}$. Since the cost of repaying the promise does not vary with the state while the default cost is increasing with $A$, if there is equilibrium default, it will happen in the low $A$ states. In particular, if the borrower invests $k$ and sells a promise $p$, she will default in all the states such that $A \leq \frac{p}{\delta k^{\alpha}}$.

As a consequence, the equilibrium price of the promise is given by

$$
q(p, k)=1-F\left(\frac{p}{\delta k^{\alpha}}\right)
$$

The problem of the borrower is then

$$
\max _{p, k} u(q(p, k) p-k)+\int_{0}^{\frac{p}{\delta k^{\alpha}}} u\left((1-\delta) A k^{\alpha}\right) d F(A)+\int_{\frac{p}{\delta k^{\alpha}}}^{\infty} u\left(A k^{\alpha}-p\right) d F(A) .
$$

The equilibrium is characterized by a couple $p, k$ which solve (5) and (6). It can be immediately shown that equilibria in this economy are, generically, Pareto-inferior to equilibria in the corresponding ADLE economy. Also, for many parameter values equilibria in this set-up differ from those in the ADLE economy along two important dimensions: $(a)$ there is a positive measure of realizations of A for which default occurs and $(b)$ there is a positive measure of values for $\delta$ for which welfare is decreasing in the strength of enforcement. As a simple example, consider the case in which $A$ can take only two values: a high value $A_{h}$ with probability $\pi$ and a low value $A_{l}$ with probability $1-\pi$, with $\pi>A_{l} / A_{h}$. In this case, in general, there exists a range of values for $\delta$ for which the equilibrium promise $p$ and capital $k$ satisfy

$$
\delta A_{l} k^{\alpha}<p<\delta A_{h} k^{\alpha},
$$

so that default happens only when state $A_{l}$ is realized and consequently $q(p, k)=\pi$. Now consider the effect of a marginal reduction in $\delta$. Equation (7) shows that, if the borrower kept $k$ and $p$ unchanged in response to the change in $\delta$, default patterns, and hence $q(p, k)$, would not change; however reducing $\delta$ increases the returns of borrower in the default state so her utility would 
increase relative to the initial equilibrium. Here weakening enforcement allows the borrower to implicitly transfer, through default, more resources to the low $A$ state and thus to achieve a better allocation of risk across states. In the ADLE economy this transfer was achieved through the Arrow-Debreu promises so default was not necessary. When promises cannot be make statecontingent increasing payoffs in the default states is the only way of obtaining this transfer.

In this simple example weakening enforcement does not affect default frequency, but in more general set-ups it does and, as a consequence, increases equilibrium interest rates and hampers intertemporal exchange. This effect is detrimental for welfare. But the example above suggests that the detrimental effect can be offset by the positive effect of the better risk allocation across states. Numerical examples suggest that this can also happen, for example, when $F(A)$ is log-normal.

\section{Summary}

Limiting contract enforcement in otherwise frictionless environments constrains intertemporal exchange and hampers risk sharing and welfare, but does not induce default. When additional frictions, such as incomplete markets or private information, limit the span of tradable promises, then limited enforcement can play a positive role by inducing equilibrium default, which can be used as a, costly, way of providing better allocation of risk across states. The analysis sheds light on how enforcement policies should be related to the observed frequency of default.

When limited enforcement is the only friction, default is never observed, yet tightening enforcement is socially beneficial. When limited enforcement coexists with other frictions, default happens in equilibrium but this does not necessarily mean that enforcement should be tightened. Indeed, tightening enforcement without ameliorating the additional friction might reduce default, but also risk sharing and welfare.

Fabrizio Perri

See alsothe entries: risk sharing; sovereign debt

\section{Bibliography}

Alvarez, F. and Jermann, U. 2000. Efficiency, equilibrium, and asset pricing with risk of default. Econometrica 68, 775-97.

Dubey, P., Geanakoplos, J. and Shubik, M. 2005. Default and punishment in general equilibrium. Econometrica 73, 1-37. 
Kehoe, P. and Perri, F. 2002. International business cycles with endogenous incomplete markets. Econometrica 70, 907-28.

Kehoe, T. and Levine, D. 1993. Debt-constrained asset markets. Review of Economic Studies 60, 865-88.

Kocherlakota, N. 1996. Implications of efficient risk sharing without commitment. Review of Economic Studies 63, 595-609.

Krueger, D. and Perri, F. 2006. Does income inequality lead to consumption inequality? Evidence and theory. Review of Economic Studies 73, 163-93.

Zame, W. 1993. Efficiency and the role of default when securities markets are incomplete. American Economic Review 83, 1142-64. 